\title{
Treatment-Associated Anxiety among Pregnant Women and their Partners: What is the Influence of Sex, Parity, Age and Education?
}

\author{
Behandlungsängste bei Schwangeren und ihren Partnern. \\ Welchen Einfluss haben Geschlecht, Parität, Alter und Bildung?
}

Authors

Affiliation
K. Kannenberg, J. Weichert, A. Rody, C. Banz-Jansen

Klinik für Frauenheilkunde und Geburtshilfe, Universitätsklinikum Schleswig-Holstein, Campus Lübeck, Lübeck

\section{Key words \\ - pregnancy \\ - pregnancy-related anxiety \\ - expectant couples \\ Schlüsselwörter \\ - Schwangerschaft \\ - Schwangerschaftsängste \\ ○ werdende Eltern}

Deutsche Version unter: http://dx.doi.org/ 10.1055/s-0042-101546

received $\quad 28.12 .2015$

revised 17.1.2016

accepted 23.1.2016

Bibliography

Dol http://dx.doi.org/ 10.1055/s-0042-101546

Geburtsh Frauenheilk 2016; 76: 809-813 @ Georg Thieme

Verlag KG Stuttgart · New York . ISSN 0016-5751

\section{Correspondence}

PD Dr. Constanze Banz-Jansen Universitätsklinikum SchleswigHolstein, Campus Lübeck Klinik für Frauenheilkunde und Geburtshilfe

Ratzeburger Allee 160

23538 Lübeck

banzcon@hotmail.com

\section{Abstract}

$\nabla$

Background: Anxiety during pregnancy can influence outcomes negatively. The aim of this study was to assess the fears of expectant parents in the setting of antenatal and obstetric care according to their sex, age, parity and education. Methods: 259 pregnant women and 183 partners, who had presented for antenatal investigation, routine antenatal care or for delivery in the UKSH women's hospital, Lübeck campus, completed a self-assessment questionnaire of fears and the German version of the STAI (Laux et al.). ANOVA and t-tests were used for significance testing.

Results: Pregnant women had higher levels of trait anxiety and state anxiety than their partners. Level of education had a significant, inverse effect on trait anxiety. Age had no influence. Fears for the child's health ranked highest among pregnancy-specific fears. Expectant fathers had the same level of anxiety for the birth irrespective of parity; for women fear of the birth decreased with increasing parity. Anxiety only increased significantly for expectant fathers from the 20th week of gestation onwards.

Conclusions: Pregnant women and their partners have different levels of anxiety dependant on their age, education, parity and the stage of pregnancy. These findings could contribute towards improving support of couples during pregnancy. The fears of expectant fathers require particular attention.

\section{Introduction \\ $\nabla$}

Pregnancy is an extraordinary time for every woman and it is experienced very differently by each individual. It is generally associated with in-

\section{Zusammenfassung \\ $\nabla$}

Hintergrund: Angst in der Schwangerschaft kann das Outcome negativ beeinflussen. Ziel dieser Studie war es, die Ängste der werdenden Eltern in Abhängigkeit von Geschlecht, Alter, Parität und Bildung im Rahmen der pränatalen und geburtshilflichen Betreuung zu betrachten.

Methode: 259 Schwangere und 183 Partner wurden mittels eines Fragebogens zur Angstselbsteinschätzung sowie dem STAI in deutscher Fassung von Laux et al. befragt. Sie stellten sich zur Pränataldiagnostik, Schwangerschaftsvorsorge oder Geburt in der Frauenklinik des UKSH, Campus Lübeck vor. Der Signifikanz-Test erfolgte mittels ANOVA und t-Test.

Ergebnisse: Die Schwangeren weisen eine höhere Eigenschafts- und Zustandsangst auf als ihre Partner. Bildung beeinflusst die Eigenschaftsangstwerte bei den Frauen reziprok signifikant. Das Alter hat hingegen keinen Einfluss. Bei den schwangerschaftsspezifischen Ängsten steht die Gesundheit des Kindes im Vordergrund. Werdende Väter haben, unabhängig von der Parität, gleich viel Angst vor der Geburt; bei Schwangeren nimmt diese mit Zunahme der Parität ab. Bei den werdenden Vätern steigen Ängste erst ab der 20. SSW signifikant an.

Schlussfolgerung: Schwangere und ihre Partner zeigen in Abhängigkeit von Alter, Bildung, Parität und Schwangerschaftsalter verschiedene Angstlevel. Diese Ergebnisse könnten dazu beitragen, die Paare besser durch die Zeit der Schwangerschaft zu begleiten. Besonders die Ängste der werdenden Väter sollten adressiert werden.

calculable risks, such as fetal malformations or maternal illnesses that may affect the child.

These dangers cause manifestations of anxiety not only in pregnant women but also in their partners, the expectant fathers. 


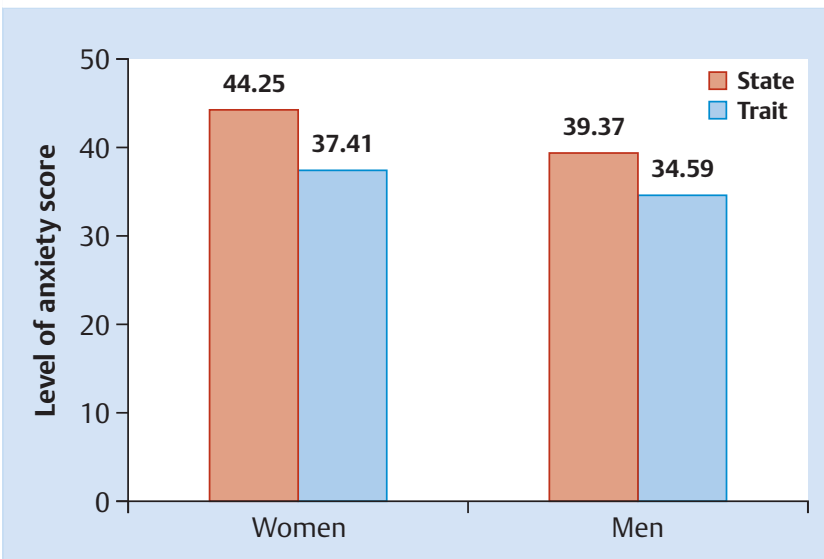

Fig. 1 Average state and trait scores.

Children of mothers suffering multiple anxieties and high levels of stress during pregnancy have been shown to have reduced birth weight, with potential consequences for their subsequent development, and more commonly have behavioural problems in the area of social interaction [1,2].

Exactly how fathers experience pregnancy has been little studied. The usual focus of investigation is how the birth is experienced and this is usually different for fathers and mothers [37].

Depending on its origins, anxiety can be differentiated into state anxiety and trait anxiety [8]. State anxiety (also "situational anxiety") is determined by factors pertaining to specific situations and is usually caused by external stimuli. State anxiety is temporary and limited to specific situations. Trait anxiety (also "characteristic anxiety") refers to a person's general disposition. Anxiety prone people experience anxiety more readily in response to many general stimuli [9].

The aim of this study was to determine whether pregnant women and their partners are affected by anxiety differently at various stages of pregnancy, and to determine whether this was dependant on their education, number of children, their age or reasons for presenting to medical services. This knowledge should enable better individual management of anxiety in the care of pregnant women and their partners.

\section{Methods}

\section{Patients}

Data acquisition for this cross-sectional study took place at the UKSH Department of Obstetrics and Gynaecology, Lübeck campus. Pregnant women and their partners who presented to this institution for antenatal ultrasound assessment, general antenatal care or for delivery formed the study population. The study was approved by the local ethics commission before commencement. 442 probands including 259 pregnant women and 183 expectant fathers were interviewed between August 2012 and August 2013.

\section{Questionnaires}

Tools used were the STAI (State-Trait Anxiety Inventory) of Laux et al. (1981) [10] and a self-assessment questionnaire of fears related to various pregnancy-specific situations (pregnancy fears -
"Schwangerschaftsängste" - groups 1-4 [SSÄ 1-4]: 1. examination situation; 2. examination results; 3 . birth/delivery; 4 . postpartum period). Patient-specific data including "reason for presentation" (indication), "age", "educational attainment”, "number of children" and "gestational age" were collected. Written consent was obtained from all study participants.

The choice of answers for pregnancy-associated fears was as follows: The stated situation makes me: "not at all anxious" =1, "a little anxious" $=2$, "fairly anxious" $=3$ or "very anxious" $=4$.

Person-specific data served to allocate probands to groups allowing comparison based on state, trait and pregnancy-specific anxiety scores. For pregnancy-specific anxieties groups of 5-8 questions were formed covering various themes.

Overall four pregnant women's questionnaires and one partner's were excluded from the analysis because consent was lacking. Questionnaires with less than $50 \%$ of questions answered were also excluded.

For inclusion subjects had to be over the age of 18 years and have sufficient German language proficiency to fully understand the questions. Questionnaires had to be completed before the birth of the child.

\section{Analysis}

Statistical analysis was performed using the SPSS Statistics 20.0, significance testing with univariate factor ANOVA and t-tests. The factors "indication" (reason for presentation), "age", "education" (categorised according to educational attainment: none/lower secondary school [Hauptschule]/comprehensive secondary school [Realschule]/university exemption/higher education), "number of children" (counting children from other relationships) and "gestational age" were analysed after step-wise testing for normal distribution using univariate factor ANOVAs (analysis of variance) taking participant's sex into account. In each case this resulted in two main effects (indication/age/number of children etc. and sex) and the effect of their interaction. Since multilevel main and interaction effects only indicate the existence of an effect and not its precise meaning, further t-tests were performed for significant findings (main or interaction effects) to further characterise them statistically. Effects were supported by their relevant statistics (ANOVA: f-value, t-test: t-value), significance level (p-value) and when possible the effect strength ( $r$ ). Small effects are defined by an $r$ of 0.1 , moderate effects by an $r$ of 0.3 , and large effects $r \geq 0,5$ [11]. An ANCOVA was used to calculate the dependence of the main effects education and age on each other by calculating the effect's ANOVA using a covariate.

\section{Results}

$\nabla$

Pregnant women had higher levels of trait anxiety and state anxiety than expectant fathers (women: trait average score $=37.41$; state average score $=44.25$; men: trait average score $=34.59$; state average score $=39.37$ ( $\nabla$ Fig. 1 ). Trait scores of the study population as a whole correlated well with those published by the German STAI [10].

There were however significant differences for trait scores between the different education level groups, with lower level education associated with increased trait scores $(p=0,004)(\bullet$ Fig. 2 ). 


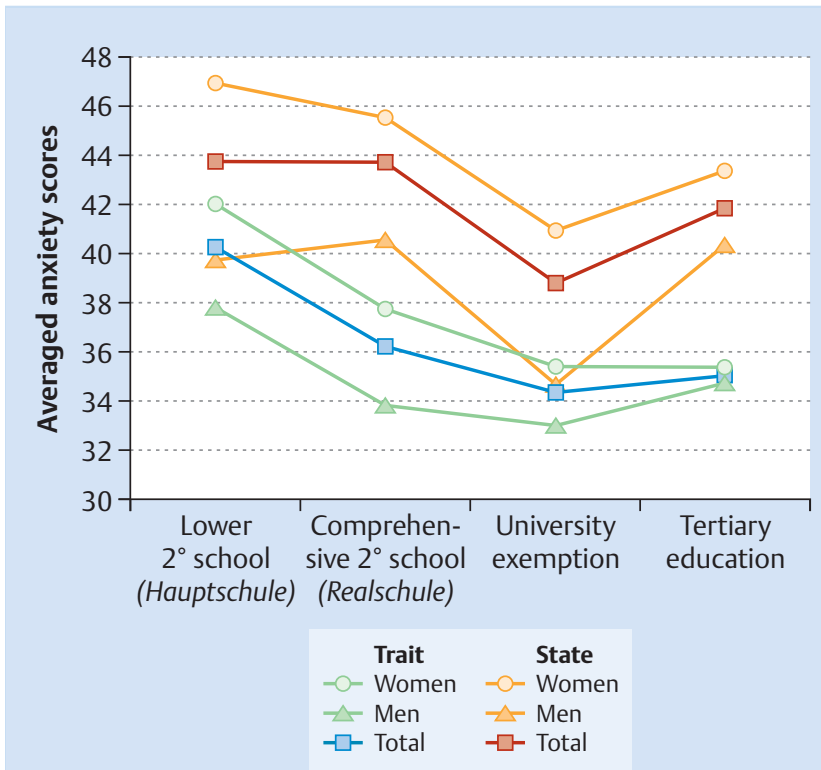

Fig. 2 Relationship between education and anxiety.

\section{Women's fears}

Among women the main effect "education" was significant for trait scores $(p=0.001)$ and remained so after consideration of subject's age $(p=0.009)$. Age therefore did not have a significant influence on the main effect "education". This result demonstrates that the trait score, as an indicator of stable tendency to anxiety inherent to the individual personality (trait), falls as education level rises, and that this effect is not due to simultaneously increasing age of expectant mothers. Thus trait anxiety in pregnant women falls with increasing level of education and this is not affected significantly by age.

\section{Men's fears}

Among expectant fathers state anxiety fell significantly with increasing number of children ( $p=0.005)$.

However there was a significant increase in trait anxiety $(\mathrm{p}=0.044)$ and state anxiety $(\mathrm{p}=0.016)$ as pregnancy progressed (๑ Fig. 3).

Men thus have significantly more pregnancy-associated anxiety at the end of pregnancy than at the beginning and midway through pregnancy.

\section{Fears specific to pregnancy}

Fear of examination situations was increased among men and women with higher education levels $(p=0.010)$. In pregnant women these fears decrease with increasing parity $(p=0.019)$.

Anxiety associated with possible investigation results increased with increasing education level $(\mathrm{p}=0.002)$. In partners this anxiety increased with increasing gestational age in contrast to that reported by pregnant women $(\mathrm{p}=0.012)$.

Anxiety surrounding the birth decreased with increasing age $(p=0.008)$. Among pregnant women it also decreased with increasing parity $(\mathrm{p}=0.006)$ whereas no significant difference was seen among expectant fathers ( Fig.4). Anxiety rose in both men and women as gestational age increased $(p=0.001)$.

Overall concerns for disease in the child constituted the greatest source of anxiety for both parent groups ( $\bullet$ Fig. 5).

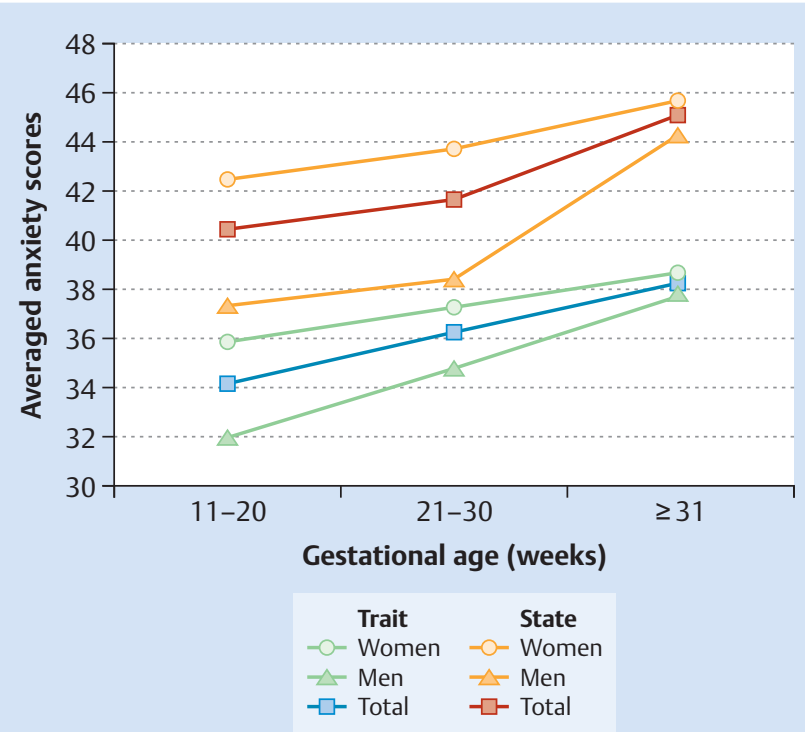

Fig. 3 State and trait scores in relation to gestational week.

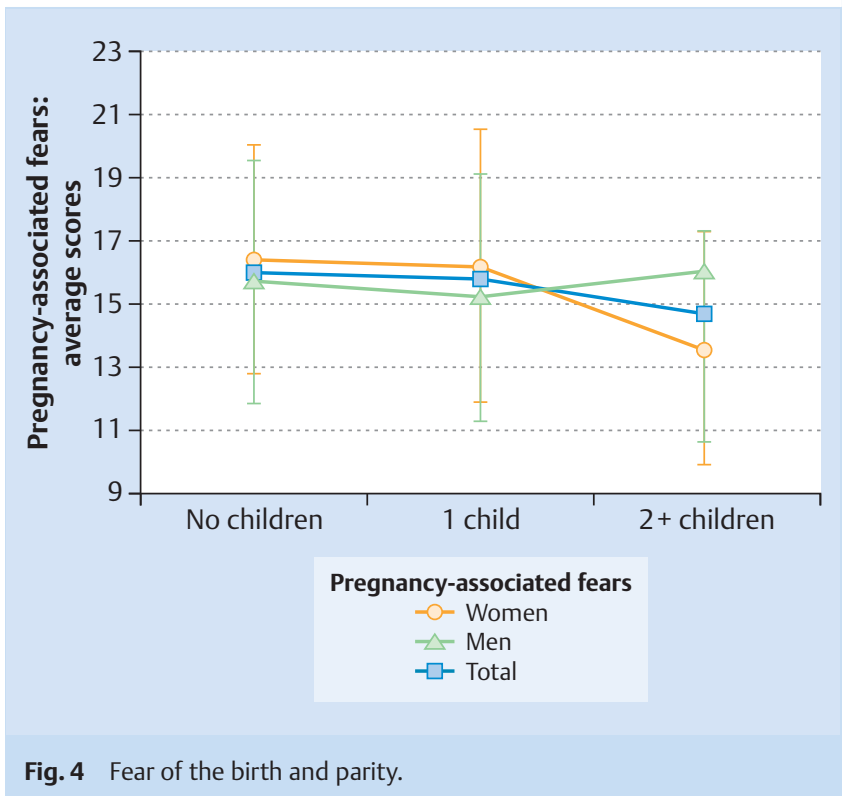

\section{Discussion}

Presentation of pregnant women and their partners to the women's hospital in the context of prenatal assessment, for acute problems or imminent delivery was accompanied by increased state anxiety (situational anxiety) compared to trait anxiety (characteristic anxiety) for both men and women. The increased state anxiety scores can be partially explained by the fact that the study population consisted exclusively of couples/pregnant women presenting to hospital, who naturally have a higher complication risk than those who only attend practice gynaecologists or receive midwifery care only. Women with higher trait anxiety 


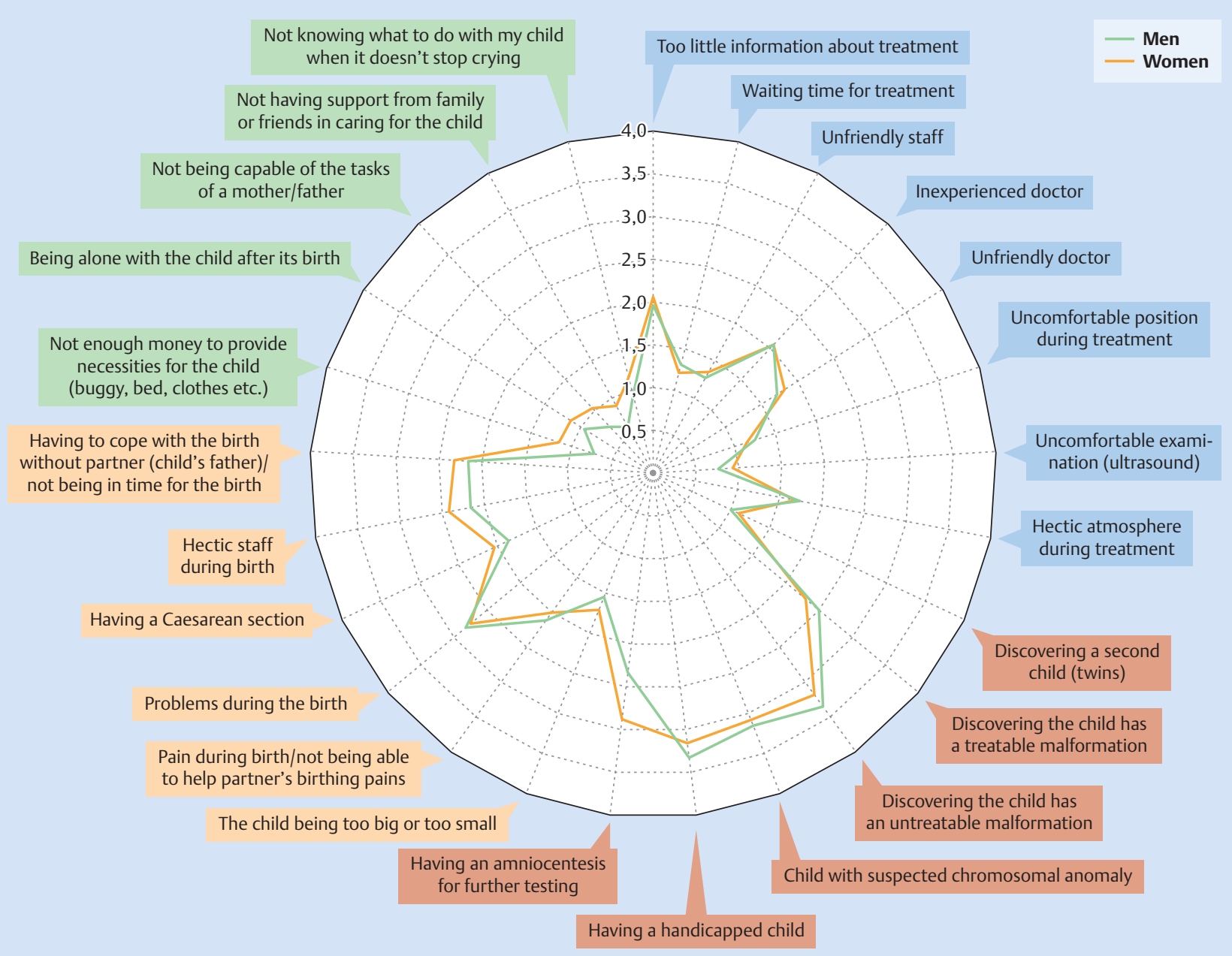

Fig. 5 All items of the specific questionnaire concerning anxiety triggers in pregnancy in numerical order.

scores (characteristic anxiety) are probably more likely than those with lower trait anxiety to seek out additional medical care and present to hospital when confronted with unfamiliar situations.

Better education generally has a positive effect on trait anxiety, probands with higher levels of education in our study population showing lower trait scores. Better education presumably gives them more access to information and more control of their lives, thus giving them a higher level of self-assuredness. This seems the most plausible explanation for the low trait scores among probands with higher levels of education [12].

The falling trait and state anxiety scores as age at delivery increases can also be explained by higher education levels with increasing age. It is evident that a higher level of education often leads to later parenthood [13]. Among women in particular, those with better education presumably have a better understanding of how to deal with their fears. Thus it is level of education and not age that appears to be the primary, decisive factor influencing state and trait anxiety scores! Our data contradict the results of Aasheim and colleagues, which regarded increased maternal age as a cause of raised anxiety levels [14].

The number of children a parent has influences anxiety scores significantly, particularly among expectant fathers. Not unexpectedly fathers of multiple children have considerably lower state scores than fathers of a single child or those with no children. This can be explained by greater previous experience in dealing with children and having experienced numerous previous pregnancies and births [15].

Expectant fathers show an evidently greater increase in state and trait scores during the course of their partner's pregnancy than pregnant women themselves. Thus expectant fathers have an increased requirement for support that specifically addresses these fears, in particular as the expected delivery date approaches.

Overall, the most significant anxiety among expectant parents is fear for the unborn child's health, followed by anxiety surrounding the birth/delivery. Most women and men do not experience the period following the birth as anxiety-laden.

Problems during pregnancy such as the fear of a fetal malformation are experienced as more anxiety-provoking by expectant parents with higher levels of education than those with lower level education. This is contrasted by lower trait anxiety among women with higher levels of education. This may be due to better knowledge of possible problems in pregnancy and birth among better educated women leading to fears being more specific, whereas women with poorer education are more likely to express their fears as nonspecific trait anxiety. There were no differences between education level groups regarding fears surrounding the birth itself. This event appears to be perceived as 
equally daunting by all expectant parents and does not seem to be influenced by knowledge or education.

In addition, expectant fathers do not show reduced scores for fear of the birth with rising number of children. The birth of each child is perceived as an equally extraordinary and evidently daunting event. It can be assumed that the father's powerlessness and mere spectator role during delivery are expressed as increased anxiety scores independent of number of children. In contrast, women show reduced scores as parity increases, which is probably explained by the self-confidence and experience gained from previous deliveries.

Overall in our study women had higher anxiety scores than men. Firstly women have generally higher state and trait scores than men [10], and secondly it is thought that their direct involvement and experience of pregnancy contributes significantly to their higher anxiety levels. However expectant fathers also develop pregnancy-associated and birth-associated anxiety, especially in the second half of the pregnancy. There is therefore an urgent need for expectant fathers to be actively engaged with and their fears addressed. This would be best accomplished through specific questions for fathers regarding their fears, asked both in the presence of their partners and alone in order to avoid reciprocal alarm, to strengthen the couple and provide optimal support through pregnancy and birth.

\section{Conclusion}

$\nabla$

- Throughout pregnancy pregnant women have higher trait and state anxiety levels than their partners.

- Among women education has a greater influence than age on trait anxiety. Increasing education levels lead to less trait anxiety.

- Trait and state anxiety only increase significantly in expectant fathers from the 20th week of gestation onwards.

- Both pregnant women and their partners report significant anxiety for the birth.

- Women with two or more children fear giving birth less than those giving birth for the first or second times, whereas expectant fathers report fear for the birth independently of parity.

This study was awarded the "Stiftung Frau-Kind-Gesundheit Dr. Rockstroh 2014" (engl.: woman-child-health trust Dr. Rockstroh 2014) prize at the congress of the German Society for Obstetrics and Gynaecology.

\section{Acknowledgements}

$\nabla$

We would like to thank all the pregnant women and expectant fathers for their participation in the study. We also thank Frau PD Dr. Annika Waldmann for statistical advice.

\section{Conflict of Interest \\ $\nabla$}

None.

\section{References}

1 Dunkel Schetter C, Tanner L. Anxiety, depression and stress in pregnancy: implications for mothers, children, research, and practice. Curr Opin Psychiatry 2012; 25: 141-148

2 Loomans EM, van der Stelt 0 , van Eijsden $M$ et al. Antenatal maternal anxiety is associated with problem behaviour at age five. Early Hum Dev 2011; 87: 565-570

3 Capogna G, Camorcia M, Stirparo S. Expectant fathers' experience during labor with or without epidural analgesia. Int J Obstet Anesth 2007; 16: 110-115

4 Chan KKL, Paterson-Brown S. How do fathers feel after accompanying their partners in labour and delivery? J Obstet Gynaecol 2002; 22: $11-15$

5 Doering $L V$, Eastwood JA. A literature review of depression, anxiety, and cardiovascular disease in women: depression, anxiety and cardiovascular disease in women. J Obstet Gynecol Neonatal Nurs 2011; 40: 348-361

6 Sapountzi-Krepia D, Lavdaniti M, Dimitriadou A et al. Fathers' feelings and experience related to their wife/partner's delivery in northern Greece. Open Nurs J 2010; 4: 48-54

7 Szeverényi P, Hetey Ané H, Münnich A et al. [Anxiety and the presence of the father at childbirth]. Orv Hetil 1989; 130: 783-788

8 Spielberger $C D$. Streß und Angst: Risiko unserer Zeit. Weinheim: Beltz; 1980

9 Schmielau F, Schmielau-Lugmayr M. Lehrbuch der Medizinischen Psychologie. Göttingen, Toronto, Zürich: Hogrefe ; 1990: 120-125

10 Laux L, Glanzmann P, Schaffner P, Spielberger CD. STAI - Das State-TraitAngstinventar - Theoretische Grundlagen und Handanweisungen. Weinheim: Beltz Testgesellschaft; 1981

11 Field AP. Discovering statistics using IBM SPSS statistics: and sex and drugs and rock'n'roll. Los Angeles, Calif.: SAGE; 2013

12 Rotter JB. Generalized expectancies for internal versus external control of reinforcement. Psychol Monogr 1966; 80: 1-28

13 Myrskylä M, Fenelon A. Maternal age and offspring adult health: evidence from the Health and Retirement Study. Demography 2012; 49: 1231-1257

14 Aasheim V, Waldenström U, Rasmussen S, Schytt E. Experience of childbirth in first-time mothers of advanced age - a Norwegian populationbased study. BMC Pregnancy Childbirth 2013; 13: 53

15 Pond EF, Kemp VH. A comparison between adolescent and adult women on prenatal anxiety and self-confidence. Matern Child Nurs J 1992; 20: $11-20$ 